\title{
Perspectivas católicas progressistas em saúde e direitos reprodutivos: o desafio político da ortodoxia
}

\author{
Progressive Catholic perspectives on reproductive \\ health and rights: the political challenge \\ of orthodoxy
}

Frances Kissling 1

1 Catholics for a Free Choice. 1436, U ST. NW \#301, Washington, DC 20009, U.S.A cffc@igc.org

\begin{abstract}
Catholics do not follow official Roman Catholic teachings on matters of sexuality and reproduction, including the position that contraception, even for married couples, is always evil, and that direct abortion, even to save a woman's life, is always immoral. Less well known is the extent of the Church's involvement in policy-making on these same issues. For example, it has forced the closing of in vitro fertilization (IVF) services from Poland to Uruguay. As the Church has never declared any of the dominant views, over time, regarding when a fetus becomes a person as a doctrine or dogma, there is no theological justification for the absolute condemnation of abortion. Neither is there a theory on "just abortion" similar to the "just war" that allows killing under certain circumstances. The enormous gap between the Church's positions and the views of worshippers has led Catholics to shape a workable and honorable sexual and reproductive ethic of their own. The Church could make a positive contribution if it chose to accompany people on this quest rather than to raise roadblocks.
\end{abstract}

Key words Catholicism; Abortion; Contraception; Reproductive Health; Reproductive Rights

Resumo Os católicos não seguem a doutrina Católica Romana oficial em assuntos de sexualidade e reprodução, que inclui considerar que a contracepção, mesmo para as pessoas casadas, sempre é má, e o aborto provocado, até para salvar a vida da mulher, é sempre imoral. Bem menos conhecido é o envolvimento da Igreja nas decisões políticas sobre estes mesmos assuntos. Por exemplo, a Igreja tem causado, direta ou indiretamente, o fechamento de serviços de fertilização in vitro (FIV) desde a Polônia até o Uruguai. Como a Igreja nunca declarou que quaisquer das opiniões dominantes, a longo do tempo, acerca de quando o feto se torna uma pessoa constitui uma doutrina ou dogma, não há nenhuma justificativa teológica para a condenação absoluta ao aborto. Também não há uma teoria do "aborto justo" semelhante à da "guerra justa", que permite matar em certas circunstâncias. A grande distância entre as posições da Igreja e os pontos de vista dos fiéis tem levado os católicos a desenvolvem sua própria ética sexual e reprodutiva, funcional e digna. A Igreja poderia dar uma contribuição positiva para a solução dos problemas discutidos se escolhesse estar ao lado das pessoas em sua busca em vez de por obstáculos.

Palavras-chave Catolicismo; Aborto; Contracepção; Saúde Reprodutiva; Direitos Reprodutivos 
É bem sabido que os católicos ao redor do mundo não seguem a doutrina Católica Romana oficial em assuntos de sexualidade e reprodução, que inclui a posição de que a contracepção, até mesmo para pessoas casadas, sempre é má, e que o aborto provocado, ainda que para salvar a vida da mulher, nunca é justificado moralmente e nunca deveria ser considerado legal. Os católicos também discordam da posição da Igreja no que diz respeito ao papel das mulheres nesta instituição - onde não é permitida sua ordenação a sacerdócio, excluindo-as das funções em que são tomadas decisões - e na sociedade - em que são vistas principalmente pelo prisma de sua capacidade reprodutiva e materna.

Porém, bem menos conhecida é a extensão do envolvimento da Igreja nas decisões políticas sobre estes mesmos assuntos. Sua participação tem sido efetiva em foros internacionais e debates nacionais sobre planejamento familiar, às vezes constituindo-se na voz determinante em políticas que afetam a vida e o bemestar de milhões de pessoas - católicas e não católicas igualmente. Por exemplo, a Igreja tem causado, direta ou indiretamente, o fechamento de serviços de fertilização in vitro (FIV) desde a Polônia até o Uruguai; tem mantido a distribuição de preservativos e a educação sexual fora de programas de prevenção de Aids; tem influenciado a política de ajuda financeira internacional dos EUA para planejamento familiar e eliminado referências específicas a métodos contraceptivos nos planos de ação das Nações Unidas.

Desde seu início, Catholics for a Free Choice (CFFC - Católicas Pela Livre Opção) têm examinado as dimensões políticas e teológicas das posições dos líderes da Igreja. Ao mesmo tempo, ao estudar os ensinamentos desta, o grupo têm permitido uma melhor compreensão dos direitos dos católicos. Na ultima década, o movimento das CFFC tem alcançado a maturidade na América Latina, por meio de grupos no México, Brasil, Uruguai, Peru e Argentina entre outros. Seu objetivo é ensinar o público que se pode ser católico e também apoiar a assistência legal à saúde reprodutiva.

Por exemplo, enquanto muitos assumem que a rigidez monolítica em assuntos morais é o modo católico, um maior conhecimento da tradição desta religião mostra a substancial liberdade de consciência da qual desfrutam os fiéis nas decisões morais e éticas. A consciência individual, de acordo com os documentos do Concílio Vaticano II (1965), é inviolável e deve ser seguida até mesmo quando discorda de ensinamentos da Igreja. Os católicos, obviamen- te, têm a obrigação de estudar e refletir sobre os ensinamentos da Igreja, de tentar reconciliar esses ensinamentos com as suas consciências, e de exercer grande cautela antes de rejeitar qualquer ensinamento da Igreja. A primazia da consciência é tão central nos ensinos da instituição, que deve ser seguida, ainda que o católico seja ameaçado com a excomunhão. Esta liberdade é especialmente clara quando os ensinamentos em questão não são infalíveis, não tendo sido declarados solenemente pelo Papa como livres de erro ao longo do tempo. Embora atualmente exista grande pressão dos líderes conservadores da Igreja para definir como infalíveis os ensinamentos sobre controle da natalidade e aborto, isto ainda não foi feito. O Concílio Vaticano II também afirmou que os católicos "devem reconhecer a legitimidade de pontos de vista divergentes sobre a organização dos assuntos mundanos e mostrar respeito por seus concidadãos" (Concílio Vaticano II, 1965).

Claramente, o aborto constitui a área de maior controvérsia e confusão do ensino católico. As últimas declarações do Papa e de muitos bispos implicam que as objeções da Igreja ao aborto estão baseadas em ensinamentos claros e constantes de que o feto é uma pessoa e, assim, o aborto é visto como assassinato. Isso está longe da verdade. Recentemente, em 1974, a Congregação para a Doutrina da Fé lançou um documento intitulado Declaratio de Abortu Procurato (Declaração sobre o Aborto Procurado), na qual a Congregação reiterou a oposição incansável da Igreja ao aborto em todas as circunstâncias. Entretanto, o documento teve cuidado de não chamar o aborto de assassinato. Acrescentou que a questão sobre quando o feto passa a ser pessoa não pode ser respondida pela ciência e que, entre os teólogos, há uma diversidade de opiniões sobre quando o feto obtém uma alma e, assim, torna-se uma pessoa. A nota de rodapé no documento do Vaticano afirma: "Esta declaração expressamente deixa de lado a questão do momento em que a alma espiritual se infunde. Não há uma tradição unânime sobre este ponto e os autores ainda estão em desacordo (...) Não está na competência da ciência decidir(...) É um problema filosófico (...)" (Congregatio pro Doctrina Fidei, 1974:26).

De modo geral, a Igreja nunca declarou que quaisquer das opiniões dominantes, ao longo do tempo, sobre quando o feto se torna uma pessoa era uma doutrina ou dogma. Conseqüentemente, não há nenhuma justificativa teológica para a condenação absoluta ao aborto pelos líderes católicos que o declaram uma violação do mandamento "Não matarás". E, além disso, a Igreja não proíbe de forma abso- 
luta tirar a vida. Historicamente, tem sido consistente a referência à chamada 'teoria da guerra justa', que permite matar em certas circunstâncias. Por exemplo: autodefesa, defesa contra um agressor injusto, proteção da integridade da nação e proteção de valores vistos como iguais à própria vida. No entanto, não há nenhuma teoria semelhante, do tipo do 'aborto justo'. As diretrizes que a Igreja desenvolveu para uma 'guerra justa' parecem ser dirigidas a homens. Talvez, a ausência de uma teoria de 'aborto justo' esteja relacionada à falta de reconhecimento das mulheres como adultos morais competentes, capazes de tomar decisões adequadas sobre a vida. Não se prevê um aborto em autodefesa, quer dizer, para proteger a própria vida; nenhum aborto contra um agressor injusto, que é o caso de um aborto após estupro; nenhum aborto para manter a integridade do corpo, que pode ser comparada à integridade nacional, o que incluiria o aborto para manter a saúde física e psicológica da mulher e nenhum aborto por valores considerados iguais ao da vida humana, o que incluiria a capacidade de cuidar dos filhos que já se tem.

A análise dos ensinamentos católicos levaram as CFFC, e muitos outros, a concluírem que estas posições estão baseadas em uma longa tradição de visões negativas acerca das mulheres e da sexualidade. De que outra forma explicar que, segundo a Igreja, no caso de um homem ter Aids, deve abster-se de manter relações sexuais, a pedido de Deus, para não transmitir a doença a sua esposa. Se o casal não conseguir abster-se mesmo nessa circunstância, não lhes é permitido usar camisinha. Conseqüentemente, parece que 'salvar o casamento' é mais importante do que salvar a vida da mulher.
Resistir ao Vaticano não significa opor-se à sua participação na vida pública - as vozes religiosas devem ser bem-vindas no processo político. Porém, a religião não deve desfrutar de privilégios. Os parlamentares devem avaliar as propostas da Igreja relacionadas à saúde reprodutiva da mesma forma que avaliam propostas de outras organizações não governamentais, tais como grupos defensores da saúde das mulheres e associações profissionais.

Além do mais, os legisladores devem levar em conta que o Vaticano não representa o ponto de vista de todos os católicos quanto a questões morais. Ainda com relação ao aborto, no qual a Igreja tem investido enorme energia e capital para convencer os fiéis e outros de sua imoralidade, a maioria dos católicos discorda e age de acordo com seus próprios princípios. No México, aproximadamente $70 \%$ dos católicos acreditam que se pode ser um bom cristão e ao mesmo tempo estar em desacordo com a Igreja com relação ao aborto. Na Polônia, 66\% dos católicos acreditam que o aborto deve ser legal no país. Nos Estados Unidos, a grande maioria dos católicos está em desacordo com os líderes da Igreja quanto a considerar o aborto ilegal em qualquer circunstância.

A grande distância entre as posições da Igreja e os pontos de vista dos fiéis tem levado os católicos a desenvolver sua própria ética sexual e reprodutiva, funcional e digna. As CFFC reconhecem que as pessoas têm uma forte inclinação para descobrir benefícios associados à sexualidade e à reprodução, assim como a outras esferas da vida. A Igreja poderia fazer uma contribuição positiva caso escolhesse ficar ao lado das pessoas ao invés de pôr obstáculos no seu caminho.

\section{Referências}

SAGRADA CONGREGAÇÃO PELA DOUTRINA DA FÉ, 1974. Declaratio de Abortu Procurato (Declaração sobre o Aborto Procurado).

CONCÍlIO VATICANO II, 1965. Gaudium et Spes (Constituição Pastoral sobre a Igreja no Mundo Moderno). 